\title{
Pancreatectomy for non-pancreatic malignancies results in improved survival after $\mathrm{RO}$ resection Kimberly A Varker, Peter Muscarella, Kristian Wall, Christopher Ellison and Mark Bloomston*
}

Address: Department of Surgery and Division of Surgical Oncology, The Ohio State University Medical Center, Columbus, OH, USA

Email: Kimberly A Varker - Kimberly.Varker@osumc.edu; Peter Muscarella - Peter.Muscarella@osumc.edu; Kristian Wall - Kristian.Wall@osumc.edu; Christopher Ellison - Christopher.Ellison@osumc.edu;

Mark Bloomston* - Mark.Bloomston@osumc.edu

* Corresponding author

Published: 27 December 2007

World Journal of Surgical Oncology 2007, 5:145 doi:10.1/86/1477-7819-5-145

This article is available from: http://www.wjso.com/content/5/l/145

(C) 2007 Varker et al; licensee BioMed Central Ltd.

This is an Open Access article distributed under the terms of the Creative Commons Attribution License (http://creativecommons.org/licenses/by/2.0), which permits unrestricted use, distribution, and reproduction in any medium, provided the original work is properly cited.
Received: 20 August 2007

Accepted: 27 December 2007

\begin{abstract}
Background: Pancreatectomy has a high morbidity but remains the only chance of cure for pancreatic cancer. Its efficacy for non-pancreatic malignancies is less clear. We reviewed our experience with pancreatectomy for non-pancreatic malignancies to determine outcomes and identify predictors of survival.
\end{abstract}

Patients and methods: The records of patients who underwent pancreatectomy for nonpancreatic malignancies between 1990 and 2005 were reviewed. Survival curves were constructed using the Kaplan-Meier method and compared using log-rank analysis. Cox proportional hazards was used to identify predictors of survival.

Results: 29 patients (I8 M/II F) with a mean age of 59.9 years (range 29-86) underwent pancreatectomy for non-pancreatic malignancies. 19 (66\%) primary malignancies were $\mathrm{Gl}$ in origin. Most operations were undertaken with curative intent $(76 \%)$, whereas the remainder was for symptom palliation. Pancreatectomy was completed for metastatic disease in 7 patients $(24 \%)$ or en bloc to achieve negative margins in 22 patients (76\%). Complete (i.e., R0) resection was achieved in 17 (59\%). Perioperative mortality was 3\%. Median follow-up was 15 months (range 7-172). Median overall survival was 12 months with I-year survival of $48 \%$. Significant predictors of improved survival by univariate analysis were RO resection, non-Gl primary, and pancreatic metastasectomy (vs. en bloc resection). Only R0 resection was predictive of long-term survival by multivariate analysis (median 21 months vs. 6).

Conclusion: Pancreatic resection for non-pancreatic malignancies can be completed with minimal mortality. However, incomplete resection results in poor overall survival. Pancreatectomy for nonpancreatic malignancies should only be undertaken if complete resection is possible.

\section{Background}

Pancreatic metastases represent an unusual clinical presentation. Sperti et al, in a literature review of 2044 reported pancreatic resections, found that only 46 (1.4\%) were performed for secondary tumors [1]. Interestingly, the prevalence of metastases to the pancreas at autopsy is 
reported to be as high as $11 \%$; the majority of these occur in patients with disseminated intraabdominal metastases [2]. Tumors that most commonly metastasize to the pancreas by blood-borne dissemination include renal cell carcinoma, melanoma, and breast and lung carcinomas. Colon carcinoma may involve the pancreas by direct invasion [3]. Up to $50 \%$ of patients with metastatic lesions are asymptomatic, the metastasis being detected upon routine surveillance for the primary tumor [3]. The differential diagnosis of metastases to the pancreas as compared to primary pancreatic tumors can be difficult. The presence of multiple hypervascular lesions on imaging studies suggests pancreatic metastasis (whereas primary pancreatic tumors are commonly hypovascular), but primary neuroendocrine tumor of the pancreas must be ruled out [3].

It is well documented that resection of hepatic metastases from colorectal carcinoma, sarcoma, or renal cell carcinoma achieves good survival. Similarly, resections of metastatic disease to the lungs and brain are now routinely undertaken. However, guidelines for pancreatic resection for metastatic disease remain unclear, probably due to the rarity of these tumors. While some recommend resection of pancreatic metastases only when there is no evidence of extrapancreatic disease [4], others maintain that the presence of extrapancreatic disease is not a contraindication, provided that complete resection can be achieved $[1,5]$.

Previous reports of small numbers of patients undergoing pancreatic resection for metastatic lesions have demonstrated median overall survivals of 19-42 months. Selected patients, particularly those with renal cell carcinoma, can achieve long-term survival [1,3,5-11]. These results, along with the decreased morbidity and mortality of pancreatic resection currently obtained in experienced centers, support the aggressive management of pancreatic metastases in selected patients.

We report herein our single-institution experience with 29 pancreatic resections for non-primary lesions of the pancreas, including metastases to the pancreas from previously resected primaries, as well as intraabdominal tumors with direct extension to the pancreas. We sought to determine the morbidity and mortality of pancreatic resection in patients with nonpancreatic malignancies and to identify factors predictive of overall survival.

\section{Patients and methods \\ Patients}

The records of patients who underwent pancreatectomy for non-pancreatic malignancies at the Ohio State University Medical Center between 1990 and $2005(n=29)$ were retrospectively reviewed. Both computerized records and paper charts were examined. Approval for this review was obtained from the Institutional Review Board of the Ohio State University.

\section{Eligibility criteria and patient follow-up}

Preoperative evaluation included history and physical examination; laboratory studies including complete blood count, serum chemistry, and coagulation profile; CT of the abdomen; and other imaging studies as appropriate. For patients presenting with pancreatic metastases, records from resection of the primary tumor were also reviewed. Eligibility criteria included the ability to obtain complete resection of the metastatic lesion and/or primary lesion with direct extension to the pancreas, as determined by preoperative imaging assessment; and the absence of medical comorbidities precluding operation. A minority of patients underwent operation with palliative intent. Postoperatively, patients underwent clinical and radiologic evaluation at the discretion of the attending physician.

\section{Statistical methods}

Overall survival was determined from the date of surgery until death from any cause as determined by hospital records or the Social Security Death Index [12] as of May 29, 2007. Survival curves were constructed using the Kaplan-Meier method and comparisons between curves were made using log-rank analysis. All statistical analyses were completed using SPSS v.14.0 software (SPSS, Inc., Chicago, IL).

\section{Results \\ Patients}

Between 1990 and 2005, a total of 29 patients (18 male, 11 female; mean age 59.9 years, range 29-86) underwent pancreatectomy for non-pancreatic malignancies at the Ohio State University Medical Center (Table 1). The majority of the operations (76\%) were undertaken with curative intent, and the remainder was for symptom palliation. Involvement of the pancreas by direct extension of malignancy occurred in $22(76 \%)$ patients, whereas metachronous metastases to the pancreas from distant sites occurred in 7 (24\%) patients (kidney, 4; brain, 1; esophagus, 1 ; chondrosarcoma, 1). Nineteen primaries (66\%) were of GI origin. The most common sites of primary malignancy were colorectal, gastric, and renal cell carcinoma. The majority of patients (21) underwent distal pancreatectomy; 7 underwent pancreaticoduodenectomy and one underwent total pancreatectomy. The median time from primary resection to pancreatic metastasis/ extension was 52 months (range, 13-240). Complete (R0) resection was achieved in 17 patients (59\%).

\section{Morbidity}

Operative mortality was $3.4 \%$ (one patient). Fifteen patients $(51.7 \%)$ had a total of 20 complications (Table 
Table I: Patient and tumor characteristics.

\begin{tabular}{|c|c|}
\hline Characteristic & Number (percent) \\
\hline Total patients & 29 \\
\hline \multicolumn{2}{|l|}{ Gender } \\
\hline Male & $18(62)$ \\
\hline Female & II (38) \\
\hline \multicolumn{2}{|l|}{ Age } \\
\hline Median & 60.0 \\
\hline Range & $29-86$ \\
\hline \multicolumn{2}{|l|}{ Operative intent } \\
\hline Curative & $22(76)$ \\
\hline Palliative & $7(24)$ \\
\hline \multicolumn{2}{|l|}{ Indication for pancreatic resection } \\
\hline En bloc for direct extension of primary malignancy & $22(76)$ \\
\hline Metachronous metastasis to pancreas & $7(24)$ \\
\hline \multicolumn{2}{|l|}{ Site of primary tumor } \\
\hline Colorectal & $9(31.0)$ \\
\hline Gastric & $8(27.6)$ \\
\hline Renal cell carcinoma & $5(17.2)$ \\
\hline Mesenteric fibromatosis & $2(6.9)$ \\
\hline Hemangiopericytoma (brain) & I (3.4) \\
\hline Breast & I (3.4) \\
\hline Esophageal & I (3.4) \\
\hline Gallbladder & I (3.4) \\
\hline Chondrosarcoma & I (3.4) \\
\hline \multicolumn{2}{|l|}{ Histologic diagnosis } \\
\hline Adenocarcinoma & $19(65.5)$ \\
\hline Moderately differentiated adenocarcinoma & $10(34.5)$ \\
\hline Poorly differentiated adenocarcinoma & $5(17.2)$ \\
\hline Mucinous adenocarcinoma & I (3.4) \\
\hline Adenocarcinoma not otherwise specified & $3(10.3)$ \\
\hline Signet ring & I (3.4) \\
\hline Clear cell & $5(17.2)$ \\
\hline Mesenteric fibrosis & $2(6.9)$ \\
\hline Hemangiopericytoma & I (3.4) \\
\hline Chondrosarcoma & I (3.4) \\
\hline \multicolumn{2}{|l|}{ Extent of pancreatic resection } \\
\hline Total pancreatectomy & 1 \\
\hline Distal pancreatectomy & 21 \\
\hline Pancreaticoduodenectomy & 7 \\
\hline \multicolumn{2}{|l|}{ Completeness of resection } \\
\hline RO (complete resection) & $17(59)$ \\
\hline RI (incomplete resection with microscopic disease) & $4(14)$ \\
\hline R2 (grossly incomplete resection) & $8(27)$ \\
\hline
\end{tabular}

2). Overall morbidity in this study was similar to that reported by others $[3,13]$. The most common GI-related complication was pancreatic fistula (4 patients, 13.8\%), followed by intraabdominal abscess and pancreatitis. Pancreatic fistula was defined as drainage of amylase-rich fluid any time after the third postoperative day. The most common non-GI complication was pneumonia (4 patients, $13.8 \%$ ). Two patients developed deep venous thrombosis. Six patients (20.7\%) had complications requiring reoperation. Of these, three patients were explored for small bowel obstructions failing non-operative management. One underwent operation two weeks after pancreatectomy for lysis of adhesions and again at three months for recurrent obstruction, and the other two underwent laparotomy for small bowel obstruction at one and six months postoperative, respectively. One patient underwent revision of gastrojejunostomy at six weeks postoperative, and one underwent exploration for control of gastrointestinal hemorrhage one month after the index operation. Finally, one patient was explored at nine months for small bowel obstruction and was found to have recurrent disease. The incidence of complications among those undergoing R0 resection was not different than that of patients undergoing R1 or R2 resection ( $p=1$, Fisher's exact test). Similarly, the incidence of complications among patients undergoing distal pancreatectomy was not different than that of patients undergoing resection other than distal pancreatectomy ( $p=0.25$, Fisher's exact test).

\section{Survival and prognostic factors}

The median length of hospital stay was 12 days (range, 743). At a mean follow-up of 14.2 months (range, 1-118), median overall survival was 12 (95\% CI 6.4, 17.6) months. 12- and 24-month survival was $48 \%$ and $20 \%$, respectively. At the time of analysis, seven patients (24\%) were still alive. First, the ability to obtain R0 resection was examined. R0 resection was achieved in $77 \%$ of operations undertaken for curative intent, as compared to $0 \%$ of operations performed with palliative intent (Table 3). Patients for whom R0 resection was achieved had median overall survival of $21(95 \%$ CI $3.5,38.5)$ months, as compared to six $(95 \%$ CI $3.5,8.5)$ months for those who had R1 or R2 resection ( $p=0.035$; Figure 1$)$. Predictors of improved survival by univariate analysis were R0 resection, non-GI primary, and metastasectomy as opposed to en bloc resection (Table 4). By multivariate analysis, only R0 resection was predictive of long-term survival (Table 4). We examined the same set of variables used to evaluate survival (i.e., age, gender, primary site, synchronous versus metachronous disease, disease free interval, curative versus palliative intent, extent of pancreatectomy, metastasectomy versus en bloc resection and R0 versus $\mathrm{R} 1 / 2$

Table 2: Operative complications.

\begin{tabular}{lc}
\hline Event & Number (percent) \\
\hline Mortality & $\mathrm{I}(3.4)$ \\
Complications (number of & $15(51.7)$ \\
patients) & 20 \\
Complications (total number) & $4(13.8)$ \\
Pancreatic fistula & $2(6.9)$ \\
Intraabdominal abscess & $2(6.9)$ \\
Pancreatitis & $\mathrm{I}(3.4)$ \\
Small bowel perforation with & \\
enterocutaneous fistula & $\mathrm{I}(3.4)$ \\
Anastamotic leak & $2(6.9)$ \\
Prolonged ileus & $4(13.8)$ \\
Pneumonia & $2(6.9)$ \\
Deep vein thrombosis & $\mathrm{I}(3.4)$ \\
Cerebrovascular accident & $\mathrm{I}(3.4)$ \\
Wound infection & $6(20.7)$ \\
Required reoperation & \\
\hline
\end{tabular}


Table 3: Likelihood of $\mathrm{R} 0$ resection by characteristic $(n=29$ patients).

\begin{tabular}{|c|c|c|}
\hline Characteristic & RO & $\mathbf{R} \mathbf{l}$ or $\mathbf{R 2}$ \\
\hline \multicolumn{3}{|l|}{ Intent of resection } \\
\hline Curative $(n=22)$ & 17 (77\%) & $5(23 \%)$ \\
\hline Palliative $(n=7)$ & 0 & 7 (100\%) \\
\hline \multicolumn{3}{|l|}{ Type of resection } \\
\hline $\begin{array}{l}\text { En bloc for direct extension of primary } \\
\text { malignancy }(n=22)\end{array}$ & $12(55 \%)$ & $10(45 \%)$ \\
\hline $\begin{array}{l}\text { Resection of metastasis to pancreas }(n= \\
\text { 7) }\end{array}$ & $5(71 \%)$ & $2(29 \%)$ \\
\hline \multicolumn{3}{|l|}{ Site of primary tumor } \\
\hline Colorectal carcinoma $(n=9)$ & $5(56 \%)$ & $4(44 \%)$ \\
\hline Gastric carcinoma $(n=8)$ & $4(50 \%)$ & $4(50 \%)$ \\
\hline Renal cell carcinoma $(n=5)$ & $3(60 \%)$ & $2(40 \%)$ \\
\hline Other site $(n=7)$ & 5 (7।\%) & $2(29 \%)$ \\
\hline
\end{tabular}

resection) for potential predictors of R0 resection. No factors capable of predicting $\mathrm{R} 0$ resection were identified. Next, the primary site was examined. Among patients who underwent en bloc resection for local extension to the pancreas $(\mathrm{n}=22)$, R0 resection was achieved in 12 patients (55\%), as compared to 5 of 7 patients $(71 \%)$ who underwent resection for metastases to the pancreas (Table 3 ) ( $p=0.37$, Fisher's exact test). Finally, patients with nonGI primaries had improved median overall survival as compared to those with GI primaries: 31 (95\% CI 0.0, $61.8)$ months versus $8(95 \%$ CI $4.6,11.4)$ months ( $p=$ 0.025; Figure 2).

\section{Discussion}

Herein we report one of the largest single-institution experiences with pancreatectomy for locally advanced or recurrent non-pancreatic tumors. The majority of these operations were undertaken with curative intent, complete (i.e. R0) resection being achieved in 77\%. Palliative pancreatectomy, however, did not result in complete

Table 4: Univariate and multivariate analyses for predictors of overall survival. Variables with the greatest potential impact on overall survival by univariate analysis $(p \leq 0.2)$ were entered into the multivariate model using Cox Proportional Hazards analysis. Data represent $p$ values.

Univariate Multivariate

\begin{tabular}{lcc}
\hline Age (>60 vs. $\leq 60)$ & 0.47 & -- \\
Age (continuous) & 0.52 & -- \\
Gender & 0.92 & -- \\
Primary site & 0.20 & 0.96 \\
Synchronous vs. metachronous & 0.14 & 0.69 \\
Disease free interval (continuous) & 0.29 & -- \\
Intent (curative vs. palliative) & 0.35 & -- \\
Pancreatectomy (distal vs. proximal) & 0.47 & -- \\
Metastasectomy vs. en bloc resection & 0.01 & 0.13 \\
Extent of resection (R0 vs RI/2) & 0.04 & 0.05 \\
\hline
\end{tabular}

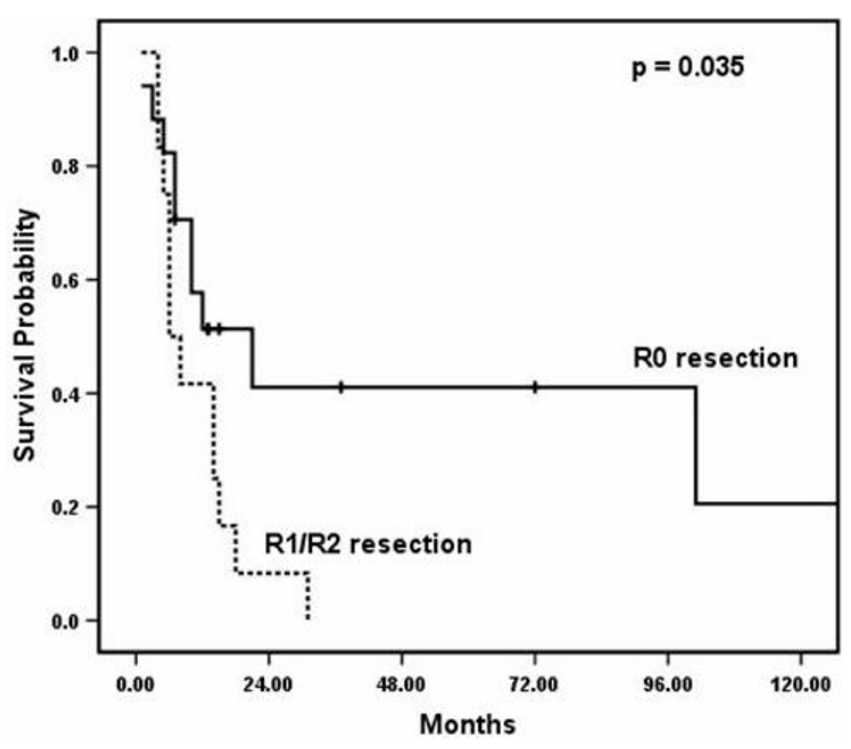

Figure I

Survival for $\mathbf{R 0}$ resection as compared to $\mathrm{R} \mathbf{I}$ or $\mathbf{R 2}$ resection. The solid line represents patients with $\mathrm{R} 0$ resection, and the dashed line represents patients with RI or R2 resection.

tumor clearance in any patient, and was associated with poorer survival. While perioperative mortality was rare (one patient), morbidity was substantial, reflecting the magnitude of the operations performed.

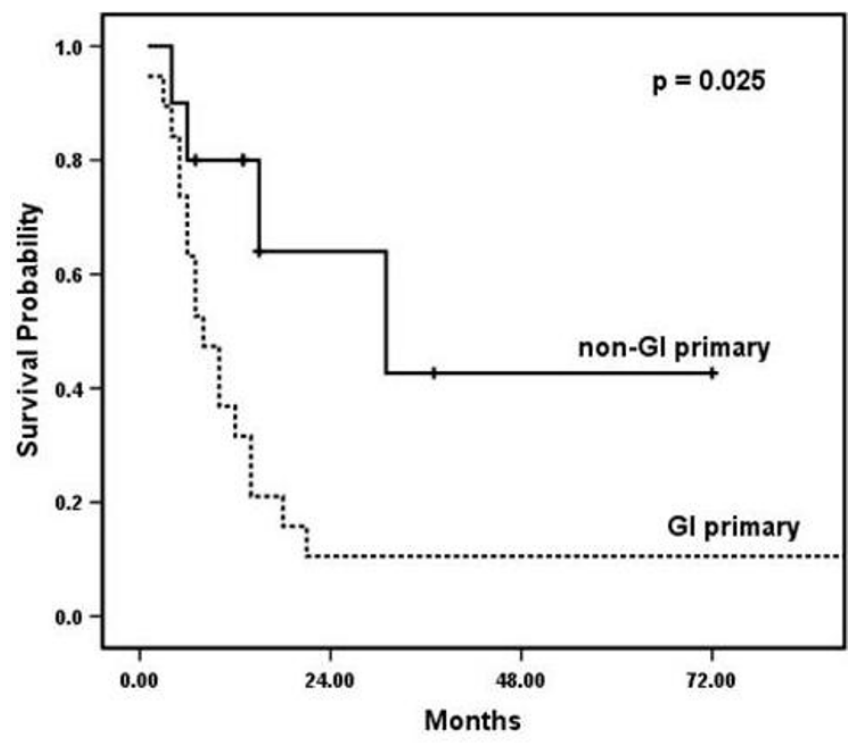

Figure 2

Survival for gastrointestinal primary as compared to non-gastrointestinal primary. The solid line represents patients with non-Gl primaries, and the dashed line represents patients with GI primaries. 
The patient population in this study was somewhat younger than typical patients undergoing pancreatectomy for pancreatic cancer, reflecting our willingness to pursue more aggressive surgical approaches in young, healthy patients. However, age was not a predictor of outcome. The majority of pancreatectomies were performed for cancers of gastrointestinal origin (most commonly colorectal carcinoma), and often for locally advanced disease. Metachronous spread of disease to the pancreas most commonly was of renal origin, as has been demonstrated previously [3,8-11]. Non-gastrointestinal primaries conferred improved overall survival as compared to gastrointestinal primaries, regardless of the completeness of resection.

In this study, we observed a median overall survival of 12 months. This is less than the survival rates reported in previous studies [1,3,5-11]. There are several possible explanations for this finding. Many previous reports of resection of pancreatic metastases include patient populations that were primarily or exclusively composed of patients with renal cell carcinoma. It is well known that metastases from renal cell carcinoma may present at a prolonged interval after resection of the primary, and that long-term survival of up to 10 years after resection of the metastatic lesion is often achieved [8-11]. Although there were five patients in our series with renal cell carcinoma, most patients had GI malignancies, which are generally characterized by shorter disease-free interval and more aggressive tumor biology. In addition, our series included 12 patients (41\%) who had R1 or R2 resections.

Several recent reports have demonstrated the utility of resection of colon carcinoma en bloc with pancreaticoduodenectomy for locally advanced disease [14-18]. Kama et al detailed the outcome of four patients who underwent en bloc pancreaticoduodenectomy with right hemicolectomy (plus resection of liver segments $\mathrm{V}$ and VI in one patient) for locally invasive right colon cancer [14]. There was one postoperative mortality but the remaining three patients had disease-free survival of 14-41 months. Berrospi et al studied three patients having en bloc resection for colon cancers involving the pancreas and duodenum; all were alive without evidence of disease at 10, 30, and 113 months, respectively [15]. Similarly, reports by Koea and Curley upon 8 and 12 patients, respectively, undergoing extended resections for colon carcinomas invading the duodenum or pancreatic head revealed low mortality and extended survival [16,17]. Finally, Kapoor et al recently evaluated their experience of 11 patients undergoing en bloc resection of adjacent organs for right colon cancer: six had en bloc pancreaticoduodenectomy; three, en bloc local excision of duodenal wall; one, en bloc resection of segments V and VI of the liver; and one, en bloc distal gastrectomy [18]. Median disease-free survival among this group of patients was 54 months. These results suggest that there may be a subgroup of patients with colorectal carcinoma, particularly right colon carcinoma, who have locally invasive disease involving the duodenum or pancreas that responds well to aggressive resection.

Many of the reports in the literature of resection for pancreatic metastases or primaries with extension to the pancreas include only those patients with margin-negative resections. For example, Pingpank et al, reported on a population of 35 patients with similar distribution of primary tumor histologies to that reported in this study [19]. However, only patients with negative margins were included. Median overall survival of 46 months was achieved. In contrast, the report by Z'Graggen et al, included 6 of 10 patients who underwent palliative procedures only [6]. In this study, a median overall survival of 19 months was observed. Thus, the lower overall survival observed in our study may possibly be explained by both the predominance of patients with GI primaries, and the fact that patients undergoing R1 or R2 resections were included. In order to truly understand the risks and benefits of pancreatectomy for non-pancreatic tumors, we felt it necessary to include all patients undergoing pancreatectomy, including those who had R1 or R2 resection.

As such, we demonstrated that $\mathrm{R} 0$ resection, as compared to $\mathrm{R} 1$ or R2, in addition to non-GI primary versus GI primary, provided statistically better survival. A univariate analysis showed R0 resection, non-GI primary, and resection of metastatic disease to the pancreas versus en bloc excision for extension to the pancreas to be predictors of survival. However, only R0 resection was predictive of survival by multivariate analysis. This result again emphasizes the fact that complete resection of metastatic or locally advanced lesions must be achieved in order to affect survival.

\section{Conclusion}

Our experience suggests that pancreatic resection for nonpancreatic malignancies can be completed with minimal mortality in experienced centers. This study, albeit relatively small, represents one of the larger experiences to date. Patients with non-GI primary tumors had better survival than those with GI primaries; however, incomplete (R1 or R2) resection resulted in the poorest overall survival, regardless of site of origin. Thus, pancreatectomy for pancreatic metastases or tumors with direct extension to the pancreas should only be undertaken if complete resection is anticipated.

\section{Competing interests}

The author(s) declare that they have no competing interests. 


\section{Authors' contributions}

KV participated in data acquisition and interpretation, wrote the manuscript, and critically reviewed the manuscript. PM participated in data acquisition. KW participated in data acquisition (chart review). ECE participated in data acquisition and critically reviewed the manuscript. MB designed the study, participated in data acquisition and interpretation, and critically reviewed the manuscript. All authors read and approved the final manuscript.

\section{References}

I. Sperti C, Pasquali C, Liessi G, Pinciroli L, Decet G, Pedrazzoli S: Pancreatic resection for metastatic tumors to the pancreas. J Surg Oncol 2003, 83:161-166.

2. Adsay NV, Andea A, Basturk O, Kilinc N, Nassar H, Cheng JD: Secondary tumors of the pancreas: an analysis of a surgical and autopsy database and review of the literature. Virchows Arch 2004, 444:527-535.

3. Crippa S, Angelini C, Mussi C, Bonardi C, Romano F, Sartori P, Uggeri F, Bovo G: Surgical treatment of metastatic tumors to the pancreas: a single center experience and review of the literature. World J Surg 2006, 30:1536-I542.

4. Roland CF, van Heerden JA: Nonpancreatic primary tumors with metastasis to the pancreas. Surg Gynecol Obst 1989, 168:345-347.

5. LeBorgne J, Partensky C, Glemain P, Dupas B, de Kerviller B: Pancreaticoduodenectomy for metastatic ampullary and pancreatic tumors. Hepatogastroenterology 2000, 47:540-544.

6. Z'graggen K, Fernandez-del Castillo C, Rattner DW, Sigala H, Warshaw AL: Metastases to the pancreas and their surgical extirpation. Arch Surg 1998, I33:413-417.

7. Hiotis SP, Klimstra DS, Conlon KC, Brennan MF: Results after pancreatic resection for metastatic lesions. Ann Surg Oncol 2002, 9:675-677.

8. Sohn TA, Yeo CJ, Cameron JL, Nakeeb A, Lillemoe KD: Renal cell carcinoma metastatic to the pancreas: results of surgical management. J Gastrointest Surg 200I, 5:346-35I.

9. Faure JP, Tuech JJ, Richer JP, Pessaux P, Arnaud JP, Carretier M: Pancreatic metastasis of renal cell carcinoma: presentation, treatment and survival. J Urol 200I, I 65:20-22

10. Law CH, Wei AC, Hanna SS, Al-Zahrani M, Taylor BR, Greig PD, Langer B, Gallinger S: Pancreatic resection for metastatic renal cell carcinoma: presentation, treatment, and outcome. Ann Surg Oncol 2003, 1 0:922-926.

II. Ghavamian R, Klein KA, Stephens DH, Welch TJ, LeRoy AJ, Richardson RL, Burch PA, Zincke H: Renal cell carcinoma metastatic to the pancreas: clinical and radiological features. Mayo Clin Proc 2000, 75:58|-585.

12. Social secrity death index (SSDI) [http://ssdi.rootsweb.com] last accessed December 22, 2007

13. Yeo Cl, Cameron JL, Sohn TA, Lillemoe KD, Pitt HA, Talamini MA Hruban RH, Ord SE, Sauter PK, Coleman J, Zahurak ML, Gorchow LB, Abrams RA: Six hundred fifty consecutive pancreaticoduodenectomies in the 1990s. Pathology, complications, and outcomes. Ann Surg 1997, 226:248-260.

14. Kama NA, Reis E, Doganay M, Gozalan U, Yasti C: Radical surgery of colon cancers directly invading the duodenum, pancreas, and liver. Hepatogastroenterology 2001, 48: I I4- I I7.

15. Berrospi F, Celis ], Ruiz E, Payet E: En bloc pancreaticoduodenectomy for right colon cancer invading adjacent organs. J Surg Oncol 2002, 79:194-197.

16. Koea JB, Conlon K, Paty PB, Guillem JG, Cohen AM: Pancreatic or duodenal resection or both for advanced carcinoma of the right colon: is it justified? Dis Colon Rectum 2000, 43:460-465.

17. Curley SA, Evans DB, Ames FC: Resection for cure of carcinoma of the colon directly invading the duodenum or pancreatic head. J Am Coll Surg 1994, I 79:587-592.

18. Kapoor S, Das B, Pal S, Sahni P, Chattopadhyay TK: En bloc resection of right-sided colonic adenocarcinoma with adjacent organ invasion. Int J Colorectal Dis 2006, 2 I:265-268. Epub 2005 Jun 7
19. Pingpank JF Jr, Hoffman JP, Sigurdson ER, Ross E, Sasson AR, Eisenberg BL: Pancreatic resection for locally advanced primary and metastatic nonpancreatic neoplasms. Am Surg 2002, 68:337-340.
Publish with Biomed Central and every scientist can read your work free of charge

"BioMed Central will be the most significant development for disseminating the results of biomedical research in our lifetime. " Sir Paul Nurse, Cancer Research UK

Your research papers will be:

- available free of charge to the entire biomedical community

- peer reviewed and published immediately upon acceptance

- cited in PubMed and archived on PubMed Central

- yours - you keep the copyright 